\title{
Marginalization in Old Age: A Case Study of Uttar Pradesh, India
}

\author{
Prashant Upadhyay ${ }^{1}$, Ruchika Singh ${ }^{2}$, \\ ${ }^{l}$ Centre for the Study of Regional Development, School of Social Science Jawaharlal Nehru University, \\ New Delhi \\ ${ }^{2}$ Centre for the Study of Regional Development, School of Social Science Jawaharlal Nehru University, \\ New Delhi
}

\begin{abstract}
In India two contradictory socio-demographic phenomena are running parallel, as India will be the youngest country in the world in near future by having largest young population in the world, but at the same time a large pool of old age population is already formed and will keep on increasing in coming time. The greying of population brings in exclusion from productive sphere of life and emanates vicious cycle of deprivation, which relegates elderly power status in family and society. This paper will look into various ways through which elderly are being marginalised in their day-to-day life by family and society in Uttar Pradesh, an elderly population majority state of India.
\end{abstract}

Keywords: Elderly, Marginalization, Socio-Economic Status, Deprivation, Logistic Regression

\section{INTRODUCTION}

Marginalization refers to the social process of becoming or being made marginal (especially as a group within the larger society) or treat (a person or group) as insignificant or peripheral or to relegate to an unimportant or powerless position within a society or group, so the dominant discourse on aging and old age have traditionally consisted of the construction of aging process of economic, social and physical decline.

The subject has deep root in human thought since virtually all individuals as well as human societies from the beginning of human history have wanted to extend life and find the magic elixir that would keep death at bay, enabling people to live long lives. Only a few really would prefer to die young and ageing societies are affluent societies. (Susan A. MacDaniel, 2008). But the process of growing older leads to popular stereotyping and attributions of discriminations (e.g. Featherstone and Wernick 1995; Biggs 1993; Elias 1985). Here, writers comprehend that in the cultural imaginations of social and economic institutions, there is an association between the presumed effects of ageing and the nature of older people. Various theories of disability identify the cultural fears of distance from the physically fit younger people to the senile older, so a distinct kind of cultural perplexity is created due to perceptions of the distance of the elderly from this ideal. Even relatively insignificant physical manifestations of difference can turn into markers of otherness. Retirement from the job provides an established cultural benchmark to entry into 'old age'. This reflects the institutionalised patterns of differentiation across the life course disclose an age segregated society and strengthen, as well as draw on, ideas about differential competencies (Hockey and James 1993; Riley et al. 1994). Some commentators argue that the perceived proximity of older people to death positions them as reminders of human mortality. Existential anxieties surrounding death mean that there is a further embedding of the idea of older people as 'others'. For Elias, social and death denial, whilst for Marshall, there is a society-wide devaluation of those seen to temporally proximate to death. (Marshall 1986). For some writers, practices of difference are so embedded in the cultural psyche that they contribute a edge to the experience of growing older. The mask of ageing has been advanced as a description of a tension between bodily appearance and capacities on the one hand, and selfidentity on the other (Featherstone and Hepworth 1991). The mask refers to the ageing body or 'exterior' which hides the true, young, spirit, 'within'.

Various writers in their research argue a historical decline in the prominence of class, and an increase in the prominence of status and division on the basis of consumption, in creating people's identities and in structuring social inequality. In this context, the stress was put on the growing significance of forms of agebased difference and inequality (e.g. Preston 1984, Turner 1988, Foner 1988, Hockey and James 1993). It was argued that being in the employment and earning for the self and to the family members play a crucial role in social inclusion. Participation in paid employment is fundamental to social identity and prestige and those not so engaged are seen to be marginalised in a variety of ways. Some scholars confine their argument by stating that recent decades have seen an unchanging state of affairs, with the increase of individualism aggravating marginalisation to those around the perimeters of the productive sphere (Hockey and James 1993). Society gives 
the importance to the independence over dependence at any point of the time of the life once an individual is the adult and can sustain his/her economy. Independence is highly valued, dependence is increasingly problematic. Compartmentalization on the basis of separate age group or equal age generations becomes very significant as identification of social differentiation and inequality. The margin of this compartmentalization is basically the transition points between childhood, independent adulthood and retirement/old age. This phenomenon we can observe in the intergenerational completion in the job market and out of such conflict of interest, within the setting of an impersonal, highly- differentiated society with the emphasis on youth and new occupations, older people are eventually pushed out of the labour market. In the modern world, this has led to the phenomenon, which we know as retirement, aggravated the situations of loss and decline in income and resulting into decline into the status of elderly.

With the increasing age, people withdraw voluntarily from roles and relationships or alternatively that they form a sub-culture distinct from wider society (Alan Walker 1980). Independent adulthood is the key to inclusion and relative advantage, whilst childhood, youth and later life are characterised as socially disadvantaged or marginalised positions. The young and the old are seen to experience exclusion from various forms of meaningful social participation and their voices are unlikely to be heard in contemporary society. In all these approaches life course stages, in particular, as they cleave around the tripartite division between childhood (and youth), 'independent adulthood' and later life, appear to have a new significance as a dimension of inequality. Quite how these dimensions should be placed within a more general theorization of inequality is less well established (Irwin, S. 1999).

There is an institutional and structural marginalisation in old age which is inevitable, so the proposed study will deal the issue of marginalisation. Nature and type of problem elderly are facing and how the elderly cope with the emerging challenges coming out due to structural transformation. Some variables have been used to prepare the deprivation index which also leads to marginalisation in the old age. Binary Logistic regression is been used to analyse the effect of certain explanatory variables on the dependent variable.

\section{Study Area}

Uttar Pradesh is most populous state of India, which constitutes around 17 percent of the total population of India. The role of this state becomes very crucial in terms of demography because it effects significantly to the net performance of any demographic attribute of the India. Total 600 old age samples above the age of 60 years were collected across the three districts of the state (Deoria, Gautam Buddha Nagar, Barabanki) through random stratified sampling by using principle component analysis. So 200 samples each were taken from the three districts, half of this sample were rural and other half representing urban elderly, during a field survey of five months, from November 2015 to March 2016.

\section{Analysis}

It is quite ironical and paradoxical that old age brings respect and it also takes away the respect. This situation varies from individual to individual, from family to family and society to society. Even in India, the society which has been conventionally a rural society and still two third of the total population resides in rural areas, where elderly used to enjoy a privileged status, are nowadays astonishingly loosing respect from the youngsters. Figure 1 represents the rural-urban differentials for the loss of respects toward elderly shows that 69.7 percent elderly have said that they are facing less respect from the youngsters. This phenomenon is equal across the rural and urban spectrum; even it is slightly higher in rural areas.

Figure 1: Rural Urban Differential for the loss of Respects towards Elderly

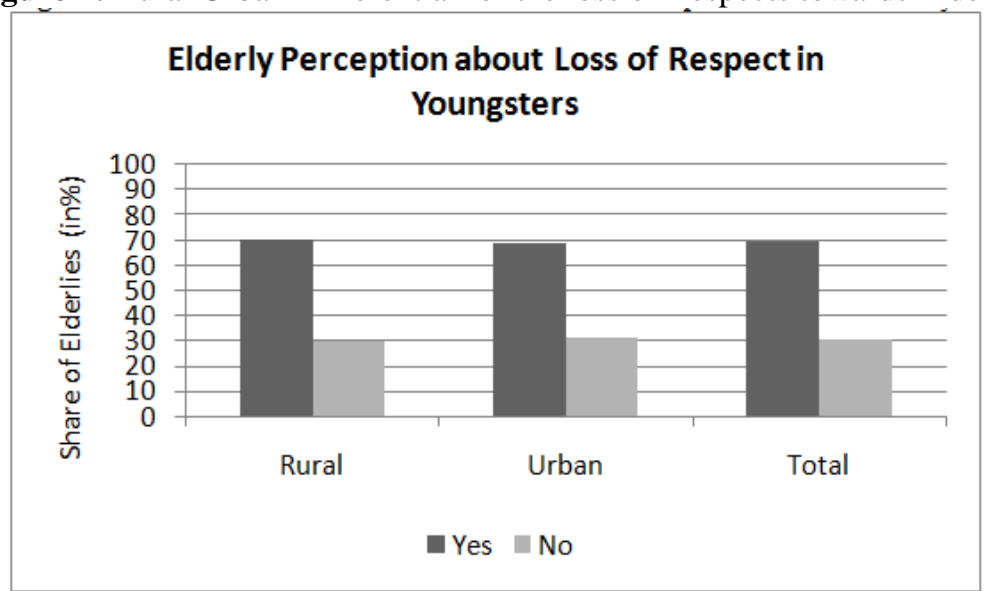

Source: Computed by Author from primary survey in Uttar Pradesh, India. 
To know the status of the elderly in the family three consecutive questions were asked regarding the process of decision making the household, like the member of the household, seek the consultation from them or not, whether family members give respect to the given suggestion or not and the third question was asked that whether they have final say in the family decision making or not.

Figure 2 represents the share of final decision maker in the family which shows an explicit declining trend in decision making in which it has been found that 84.5 percent elderly have claimed that they have been consulted in various affairs of the household but the percentage declined to around three percent when it was asked that their opinion is given respect or not and finally there is drastic fall in the response when it was asked that whether the elderly have final say in the decision of the crucial affairs of the household such as purchasing property anywhere, wedding choices of the younger members of the family and decisions regarding the agricultural purchase and sell, just 53.2 percent of the elderly have said that they have final say in the decision making. This turned out to be the more serious issue when around 81.2 percent have said that they used to enjoy the position of principal decision maker in the family when they were young and economically productive but their position in the family declined as they started to loose their economic independence. Elderly females are less asked for consultation than the male elderly member. But most of the elderly women too claimed that as their age is increasing they are loosing the previous relatively better position in the family. The conclusion can be drawn from the above figure that, traditionally, in the Indian society, although the elderly apparently seem to be respected and designated as heads of the households, they seldom enjoy the actual power or authority.

Figure 2: Elderly as a final decision maker in the household

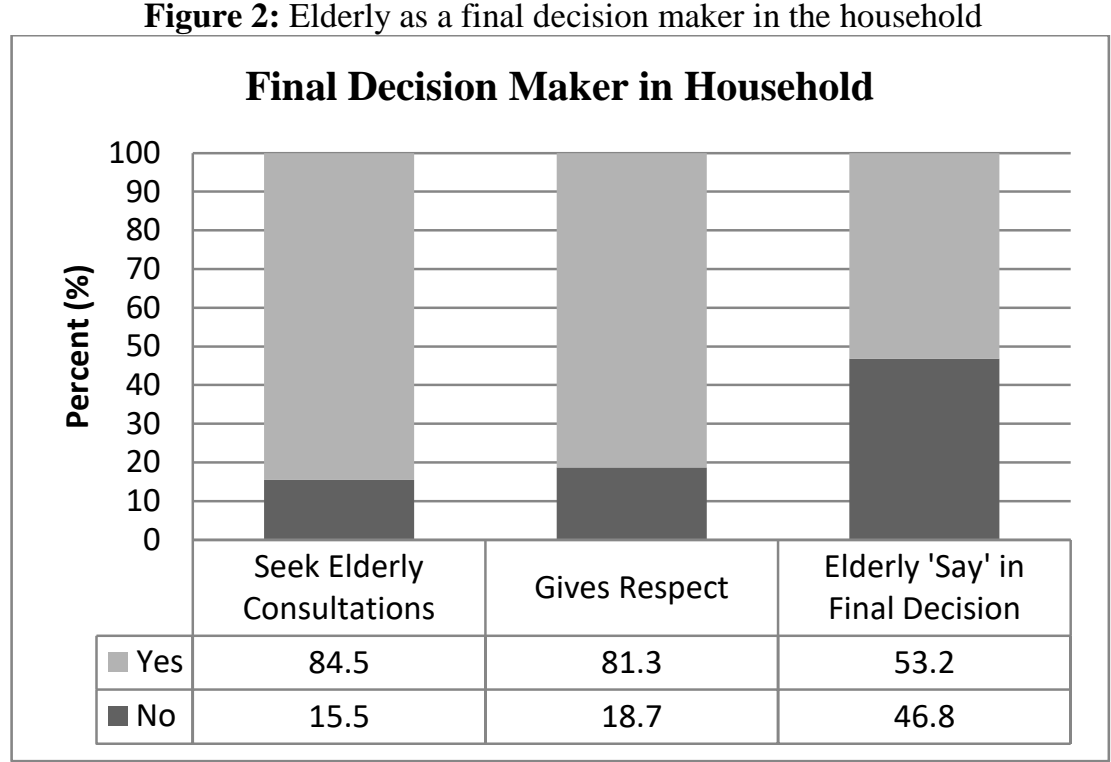

Source: Computed by Author from primary survey in Uttar Pradesh, India.

Total $53.5 \%$ elderly agreeing to the fact that society is cooperative to elderly. More than half of the elderly population (53.5 percent) has said that society is co-operative towards elderly and did not create any problem due to their age. But around 46 percent of elderly have said that the society is not cooperative towards them and have a hostile feeling due to ageism. Non-cooperation is found to be highest in Deoria, followed by Barabanki, and followed by Gautam Buddha Nagar. Non-cooperation is almost equal in Gautam Buddha Nagar, which is at around 39 percent. Non-cooperation towards male elderly is higher than the female elderly in Deoria and Barabanki. Around 48 percent elderly male have said that the society and surroundings are co-operative for them whereas 58.6 percent female elderly have said that people do co-operate with them, female elderly have reported more co-operation than their counterpart, though these figures at times hide the whole social reality which most often goes unreported through questionnaire-based research. As in India, the social reality is very complex to understand when intertwined with the various aspects of socio-spatial and gender relations, and women are very less empowered and very less aware about their rights in comparison to their male counterpart, thus it can be said that though the condition of the elderly women is worse than the elderly men in terms of getting assistance in day to day life, still they were hesitant to accept the reality and more reluctant to express the problems of their home to outsiders.

The question was asked regarding the societal experience of elderly in which elderly are experiencing the behavioural change in society towards elderly. Total $59.3 \%$ of elderly are reporting changes in the experience of societal attitude for elderly. This table shows the slight variation in male-female experience and marked distinction in regional pattern where $46.5 \%$ elderly are experiencing the change in G.B. Nagar, 57\% 
elderly experiencing the change in Barabanki and in Deoria $74.5 \%$ elderly experiencing the change. In total $58.7 \%$ males are experiencing the change in societal attitude towards elderly and among females, $60.9 \%$ are experiencing the change.

Old age is characterised as loss of physical health and social and familial capital. In such situation, there is a likelihood of developing a fear for the physical and material assets. As we have heard various news regarding, assault over elderly when they are alone at their home. Elderly become a very soft target for the miscreants to attack over the elderly whether they are at their home or outside their home because elderly are unable to produce physical resistance. 25.8 percent of the elderly population of the total sample in the study area was felt unsecured and they said that they are afraid of thieves. Fear for the thief was highest in Deoria (29.0 percent) and it was lowest in Gautam Buddha Nagar (22.5 percent).

The family system is eroding due to various factors thus leads to increase the vulnerability of elderly in their later days. Old age demands for special care and attention by their near and dear one and in the absence of care, elderly subjected to relative deprivation and poverty. Children are the basic support system in old age in the conventional society like India, but when children don't stay with the person they slowly head towards the marginalisation. Or one can say that they are marginalised due to loneliness.

More than half of the total elderly sample taken reported that their children don't stay with the elderly parents. It was highest in Deoria and was lowest in Gautam Buddha Nagar in Uttar Pradesh.

Elderly are entrapped with the loneliness sometimes due to volunteer causes and sometimes due to forced causes and sometimes due or external factors. More or less each and every elderly face certain degree of loneliness. The situation becomes even worse when their spouse is dead. Elderly don't have company to share their feelings and they miss the zeal to live a happy life without their partner. Single elderly reported two times higher loneliness than elderly living with the spouse, thus the onset of old age in it brings the notion of 'othering' and hostility from the younger generation and elderly are pushed to segregation and loneliness. So around 53 percent of elderly have claimed that they feel lonely and this percentage was higher in the case of single elderly.

From the selected samples of study area more than half of the elderly feel loneliness. Loneliness was more prevalent in urban areas than the rural areas as urban areas possess the lack of social capital due to a rapid and self-centered lifestyle of urban area where there is no space out for the elderly to interact with their neighbours and others outside the family to eliminate loneliness. Similar kind of situation is prevailing inside the family as well, where life is very busy and other family members don't found any productive output from the elderly, thus elderly found themselves lonely inside the boundary of the house also. In opposition to this, rural elderly have claimed less loneliness as they have plenty of places to roam with and always people with leisure time to do gossiping. The households of the elderly which have grandchildren and cattle both, they were found to be the busiest elderly in the household and they said that they don't experience any kind of loneliness in the family. But out-migration is very prevalent in the rural areas and this leads to younger generations migrates to the cities for the employment and leaving the elderly alone in the house though this phenomenon is not just limited to the rural areas alone, but younger generation from the towns are also migrating to other higher order cities for various aspirations thus leading the elderly couple alone in the house.

The land is a kind of resource, which generates resources itself and provides various kinds of socioeconomic security and stability. In the absence of social security from state and financial help from family, ownership of land becomes very important source of sustaining life in India, irrespective of whether someone reside in rural areas or urban area. 63.7 percent of elderly population possesses land in study area. Those have land were having better life than those who does not possess land. Elderly with large size of land were observed enjoying better life than those have small size of land. Land as a resource brings social status and prosperity especially in rural economy and it also has a very significant role in urban areas, where even a small size of land can provide a handsome amount of returns due to more economic valuation of urban land.

\section{Binary Logistic Regression Analysis}

In order to examine changes of relative position of elderly in household, binary logistic regression has been applied. The main individual level variables considered are: I. Age II. Gender III. Marital Status IV. Place of Residence V. Level of Education and VI. Income from any source. Elderly as a final decision maker or have role in the family decision making process is considered as a dependent variable. 
Table 1: Logistic Regression for Elderly Role in Decision Making in Family according to their Socio-Economic background characteristics in Uttar Pradesh, India

\begin{tabular}{|c|c|c|c|c|}
\hline & & $\operatorname{Exp}(B)$ & Sig. & S.E. \\
\hline \multirow[t]{3}{*}{ Age } & Age 60 to 69 Years (RC) & 1 & 0.426 & \\
\hline & Age 70 to 79 Tears & 1.446 & 0.259 & 0.327 \\
\hline & Age 80 Years and Above & 1.187 & 0.624 & 0.35 \\
\hline \multirow[t]{2}{*}{ Gender } & Male (RC) & 1 & & \\
\hline & Female & $0.349 * *$ & 0.051 & 0.54 \\
\hline \multirow[t]{2}{*}{ Marital Status } & Married (RC) & 1 & & \\
\hline & $\begin{array}{l}\text { Widows/ divorced/ } \\
\text { Separated }\end{array}$ & 0.801 & 0.617 & 0.445 \\
\hline \multirow[t]{2}{*}{$\begin{array}{ll}\text { Place } & \text { of } \\
\text { Residence }\end{array}$} & Rural (RC) & 1 & & \\
\hline & Urban & $0.605 * * *$ & 0.006 & 0.184 \\
\hline \multirow[t]{5}{*}{$\begin{array}{ll}\text { Level } \\
\text { Education }\end{array}$} & Illiterate $\mathbf{( R C )}$ & 1 & 0.082 & \\
\hline & Primary Education & 1.201 & 0.533 & 0.293 \\
\hline & $\begin{array}{l}\text { Middle } \\
\text { Education }\end{array}$ & 1.411 & 0.253 & 0.301 \\
\hline & Senior Secondary & 0.884 & 0.776 & 0.433 \\
\hline & $\begin{array}{l}\text { Higher and Above } \\
\text { Education }\end{array}$ & 1.628 & 0.631 & 1.015 \\
\hline \multirow[t]{5}{*}{$\begin{array}{l}\text { Income/ Earning/ } \\
\text { Remittances }\end{array}$} & Less than 500 Rs (RC) & 1 & 0.011 & \\
\hline & 500 to $2000 \mathrm{Rs}$ & 0.907 & 0.791 & 0.369 \\
\hline & 2000 to $5000 \mathrm{Rs}$ & 0.852 & 0.684 & 0.395 \\
\hline & Above $5000 \mathrm{Rs}$ & 1.189 & 0.136 & 1.007 \\
\hline & Constant & 0.681 & 0.533 & 0.616 \\
\hline \multicolumn{2}{|c|}{$\begin{array}{l}\text {-2 Log Likelihood } \\
\text { Nagelkerke R }{ }^{2} \\
\text { Model Chi-Square (Sig.) } \\
\mathrm{N}\end{array}$} & & $\begin{array}{r}57 \\
0.1 \\
24 *(.0 \\
60\end{array}$ & \\
\hline
\end{tabular}

Note: $\mathrm{p}<0.01=^{* * *}, \mathrm{p}<0.05=^{* *}, \mathrm{p}<0.1=^{*} ; \quad(\mathrm{RC})-$ Reference Category

Differentiation on the basis of place of residence and gender of elderly were found significant. Female elderly are less likely to have role in final decision making in the household. Patriarchal nature of society, widespread of illiteracy, economic and social dependency of the woman over her spouse and family are the main possible attributes for the lower status of the elderly woman in the family and thus leads to having less role in the decision-making process in the family. Urban elderly have less say in the final decision making in the family than their rural counterpart. The status of elderly were more or less same during the field observation but due to good articulation for their grievances and awareness of the urban elderly for their rights, urban elderly straightforwardly reported that they are not considered in the final decision-making process of the family and they explicitly feel loss of status in the family after retirements in old age.

As the age increases, the role of elderly in the final decision making in the family also increases but after reaching the age of 79 , the influence started to decline. Married elderly have a better role to play in the final decision making than those who are single due to death of the spouse, divorce or separation. Except for senior secondary level of education, the role elderly in final decision making in the family increases as the level of education increases. Illiterate elderly are very much ignored while taking decision in the family.

There is a sense of crisis among the elderly who are earning than those who are not earning or less earning (less than 500 rupees per month), they eloquently reported that despite contributing to the family day to day chores, their roles are declining than earlier in family decision making. But those elderly who are totally financially dependent on the family members reported that their opinions are welcomed in the family because they did not want to portray any hostility with the family members.

\section{Multiple Deprivations}

A range of data was collected on older people's income, material resources and various other aspects of the elderly for this research, which allows me to construct an index of multiple deprivations. Author has modified and developed the index which was used in the study "Older People in Deprived Neighbourhoods: 
Social Exclusion and Quality of Life in Old Age" which was published by the Centre for Social Gerontology, Keele University in 2002.

The index was modified with the consideration of socio-cultural setup of the India especially rural part of the Uttar Pradesh. In the earlier study, the index of multiple deprivation comprises seven items considered of particular importance to older people, for example, lives in the household without central heating, lives in a household without a phone, lives without a car, rented accommodation, more than one person per room, receives income support, no formal qualifications. These measures allow people to be categorised according to the degree of deprivation they face, ranging from deprivation (where a person is not disadvantaged on any of the seven categories) to high deprivation (disadvantaged on at least five characteristics).

Index of Multiple Deprivations

A person scores 1 for each of the following characteristics

- Health is not good

- Children don't stay with you

- Receives any pension or regular cash income

- Do you have bank account

- Illiteracy

- Do you have mobile

- Does the household possess latrine

No Deprivation:

Score 0: not disadvantaged on any of these characteristics Low Deprivation:

Score1-2: disadvantaged on one or two characteristics only Medium Deprivation:

Score 3-4: Disadvantaged on three or four characteristics

High Deprivation:

Score 5 or more, disadvantaged on at least five characteristics

This study found very high level of deprivation among older people in deprived rural and urban setting of Uttar Pradesh. Only a minority of respondents (7.2 percent) were not disadvantaged on any of these characteristics of deprivation. Almost 32 percent experienced low levels of deprivation. The majority of older people interviewed could be categorised as experiencing Medium level of deprivation (43 percent), being disadvantaged on three and four out of the seven characteristics. There is also very good size of the population (17 percent) falling into the category of high deprivation. Very few of the people interviewed did not report at least some disadvantage and in most cases, this was multiple rather than a single item of deprivation.

Table 2: Elderly experiencing multiple deprivations in Uttar Pradesh, India.

\begin{tabular}{|l|l|l|}
\hline Levels of Deprivation & Frequency & Percent (\%) \\
\hline No Deprivation & 43 & 7.2 \\
\hline Low Deprivation & 197 & 32.8 \\
\hline Medium Deprivation & 258 & 43.0 \\
\hline High Deprivation & 102 & 17.0 \\
\hline Total & $\mathbf{6 0 0}$ & $\mathbf{1 0 0 . 0}$ \\
\hline
\end{tabular}

Source: Computed by Author on the basis of primary survey in Uttar Pradesh, India.

Deprivation leads to a very distinguish type of marginalisation. Those who are deprived on the basis of these indicators can be categorised as marginalised and the level of marginalisation varies on the basis of the level of deprivation, as those who are less deprived are less marginalised and those who are more deprived are highly marginalised.

\section{CONCLUSION}

Family, kinship and community as informal support systems are considered strong enough to provide social security to its members, including older people in traditional Indian society. Urbanisation, industrialisation and the globalisation have done adverse effect on traditional values and norms within society. The joint family are gradually shifting towards nuclear families, economy is becoming devoid of morality, value system is changing rapidly, out-migration of youth to urban areas for better livelihood and increase in workforce participation of women are important factors responsible for the marginalisation of elderly in rural India (Vijaykumar,1999). This research paper concludes that elderly are losing respect from the younger generations. There is negatively change of societal attitude towards the elderly. Elderly are forced to live in the loneliness. 
Elderly are deprived of some very basic amenities and witnessing the loss of socio-economic status in India, thus they are being gradually marginalised by the family and society.

As India is rural country where more than its two-third of its population resides in rural areas, the issues related to elderly become very severe and this situation becomes even more severe when it comes to the elderly of Uttar Pradesh where percentage share of rural population is higher than national average. Uttar Pradesh is huge state in terms of population and area and it also consists with great diversity in terms of place of residence, social group, gender, region etc. Given the vast size and intricacies of demography, the genuine problems of the elderly are remaining unaddressed so there is urgent requirement from the policy makers to come up with some proper and concrete mechanism to address the issues related to elderly population to mitigate institutionalised marginalisation of old age population. The family and the society must realise the importance of the elderly and try to give back the elderly its revised previous cultural position and embrace the elderly as an asset rather than the liability.

\section{BIBLIOGRAPHY}

[1]. Walker, 'The Social Creation of Poverty and Dependency in Old Age', Journal of Social Policy, Vol. 9, 1,1980, p. 51.

[2]. Achenbaum, W. Andrew and Stearns, (2008) N. Peter, 'Old Age and Modernisation', in Susan A. McDaniel (ed.) Ageing, Volume 2 Forms and Practice, New Delhi: Sage Publications, pp.61-69.

[3]. Bhattacharya Prakash "Implications of an Ageing Population in India: Challenges and Opportunities" Copyright 2005 by the Society of Actuaries.

[4]. Biggs, S. (1993) Understanding Ageing. Bucks: Open University Press

[5]. Chattopadhyay Aparajita "Population Policy for the Aged of India", Economic and Political Weekly, Vol. 39, No. 43, (Oct 23-29, 2004), pp 4694-4696.

[6]. Corden Anne, "Geographical Development of the Long-Term Care Market for Elderly People", "Transactions of the Institute of British Geographers", New Series, Vol. 17, No. 1 (1992), pp. 80-94.

[7]. Dandekar Kumudini, "Mortality and Longevity in India, 1901-1961", Economic and Political Weekly, Vol. 7, No. 18 (Apr. 29, 1972), pp. 889-892.

[8]. Das, Dipendra Nath and Vemuri, M. D., (2009), "Gender Differences among older person- a study based on the 2001 population census of India", Gender Issues in Development, ed by Bhaswati Das and V. Khawas, Rawat Publications, Jaipur

[9]. Eberstadt, N. (1997) "World Population Implosion" Public Interest, 129:3-22

[10]. Elias, N. (1985) The Loneliness of the Dying Oxford: Blackwell.

[11]. Featherstone and Hepworth (1991) The Mask of ageing and the postmodern life course, in Featherstone, M., Hepworth, M. and Turner, B.S. (eds) The Body. Social Process and Cultural Theory London: Sage.

[12]. Featherstone, M. and Wernick, A. (1995) Introduction, in Featherstone, M. and Wernick, A. (eds) Images of Aging. Cultural Representations of Later L. London: Routledge.

[13]. Foner, A. (1988) Age Inequalities. Are they epiphenomena of the class system? in Social change and the Life Course (vol 3) Social Structures and Human Lives M.W. Riley with B.J.Huber and B.B. Hess (eds). London: Sage.

[14]. Gavrilov L.A., Heuveline P.“Aging of Population.”In: Paul Demeny and Geoffrey McNicoll (Eds.), The Encyclopaedia of Population. New York, Macmillan Reference USA, 2003.

[15]. H.B. Chanana and P.P. Talwar "Aging in India: Its Socio-economic and Health Implications" AsiaPacific Population Journal, Vol. 2, No. 3

[16]. Hockey, J. and James, A. (1993) Growing Up and Growing Old: ageing and dependency in the life course. London: Sage.

[17]. Kamo, Yoshinori and Min Zhou "Living arrangements of elderly Chinese and Japanese in the United States," Journal of Marriage and the Family, No. 56, 1994 : 544-558.

[18]. Karkal, M. (1999), "Ageing and Women in India", Economic and Political Weekly, Vol 34, No. 44, pp 54-56.

[19]. Kumar, Vijay S., 1999. Quality of Life and Social Security for the Elderly in Rural India. Council for Social Development, Hyderabad.

[20]. Malini Karkal "Ageing and Women in India" Economic and Political Weekly, Vol. 34, No. 44 (Oct. 30 Nov. 5, 1999), pp. WS54-WS56.

[21]. Premi, M.K.., (2009), "India's Changing Population Profile", New Delhi. National BookTrust, pp202203.

[22]. Preston, S. (1984) Children and the Elderly: divergent paths for 16 America's dependents, Demography, Vol 21, No. 4, 435-457.

[23]. Sarah Irwin (1998), "Inequality and Life Course: Sociological Theory and Later Life" Centre for Research on Family, Kinship \& Childhood, Working Paper 5. 
[24]. Subramanian, S.V. and James K.S, (2003). "Towards a Demographic Transition”. Economic and Political Weekly, Vol 38, No. 12/13, pp.19-29.

[25]. Turner, H. Jonathan (1988) A Behavioural Theory of Social Structure, Journal for theory of Social Behaviour, Vol 18 No. 4, December, 0021-8308.

[26]. Visaria Pravin, "Demographics of Ageing in India", Economic and Political Weekly, Vol. 36, No.22, (Jun 2-8, 2001), pp- 1967-1975.

[27]. Visaria, L. and P. Visaria, (2003). "Long-Term Population Projections for Major States, 1991-2101", Economic and Political Weekly, No.38(45), Nov.8, pp63-75.

[28]. Wilson G., (2006), "Local Culture, Globalization and Policy Outcome: An Example from Long-Term Care", Global Social Policy 2006, pp 6-288

[29]. Wilson Gail (2000) "Understanding Old Age-Critical and Global Perspective", Sage Publications, London.

[30]. World Population Ageing: 1950-2050.

[31]. http://www.un.org/esa/population/publications/worldageing19502050/ 